\title{
Two Recent Self-Referential Arguments
}

JOSEPH WAYNE SMITH

The Flinders University of South Australia

A critical evaluation of two recent discussions of applications of the argument from self-referential consistency (ASRC) will be examined here. In the first: paper Patrica Smith Churchland attempts to undermine John Eccles' argument that determinism is self-refuting.' In the second paper Nicholas Everitt argues that the position of "straight forward eliminative materialism" (SEM) meets the same fate. ${ }^{2}$ Here, I will argue that the arguments of Churchland and Everitt are unsound and that churchland in particular has seriously mis-stated the position of a non-trivally absurd libertarianism. However, the self-referential arguments against both determinism and eliminative materialism can be met by champions of these positions. The arguments are in fact question begging.

1. What Is ASRC?

A position criticized by an ASRC is taken to imply either: its own falsity, its own meaninglessness or indeterminancy of truth-value, although by far the most common strategy is to argue that some position implies its own falsity. Such ASRC arguments can be contrasted to the liar paradox. In the liar paradox we are asked to consider a sentence:

\section{(L) This sentence is false.}

The familiar paradox arises through considering the truth-value of (L): (L) is true if and only if it is false, and false if and only if it is true. An ASRC argument against a position $P$ would lead to the conclusion that $P$ is false if it is true, and if false, then it is false. From the perspective of two-valued logic $p$ must be necessarily false. "p" is a conjunction of sentences $\mathrm{S1} \& \mathrm{~S} 2 \& \mathrm{S3} \& \ldots \&$ Sn that a champion of a position would assent to as being an adequate description of such a point of view. Such an argument we call a semantic self-referential argument (SSRA).

There are very few examples of SSRA in the literatire. Perhaps the most well known argument is one directed against the verificationist theory of meaning 
stated by the logical positivist movement in its early days: the principle itself seemed to be condemned to the dark damp domain of the cognitively meaningless, being neither analytically true (nor a contradiction) nor directly confirmed by sensory observations. For the most part most ASRC have been pragmatic self-referential arguments (PSRA). By use of the term "pragmatic" I refer to all those aspects of a language in which explicit reference to a speaker is made. 1 Among the pragmatic concepts of a language we find the following assortment: "Subject $S$ knows that $P$," "S justifiably believes $P$," "S argues thesís $T$ ", and so on. An example of a popular PSRA is the dogmatists' response to the sceptic who claims that one is not the slightest bit reasonable in believing any propositions: the sceptic by the performance of the speech act of advancing such a thesis within the domain of philosophical discussion is advancing a thesis for our reasoned evaluation. But if this is so, the argument defeats itself.

The dogmatist's argunent can be met by the sceptic, by a strategy through which very many PSRA can be met: it in fact begs the question at issue. Our thorough going sceptic would warmly embrace irrationalism and would hardly respect the yoke of rationalism. Scepticism would be seen as a medicine for curing us of our dreaded epistemic diseases, which destroys both itself and the disease in the process. The self.-referential arguments against determinism and eliminative materialism will fail, I will argue, for the reason of being question begging.

Before turning to a consideration of churchland and Everitt's papers, one argument which would seem to rule out this inquiry needs brief consideration. Bertrand Russell's ban upon all self-referential statements because they violate what he called "the vicious circle principle" $e^{16}$ would, if satisfactory, constitute grounds for rejecting any ASRC. However one of the consequences of Russell's ban is that j.t leads us directly to the paradox of the non-communicator.? So even if we were to regiment language to avoid all self-referential statements we would not escape paradox. Since the paradox of the non-communicator follows from Russell's theory of types together with semantic principles which Russell himseli would have accepted, avoiding ASRC by this strategy is quite problematic.

\section{A Critique of Churchland's Criticism of Eccles}

A champion of a PSRA argument against determinism must assume that the thesis of the compatibility of determinism and freedom of will is false. If compatibilism was true, then the pliblosophical problem of freedom versus determinism would be solved. John Eccles is an incompatibilist: indeed the art of denying 
free will presupposes, he believes, free will to make this very denial. If deterninism was true, then our very reasoning for determinism is "merely the automatic response of a nervous system built by genetic coding and molded by conditioning"9 and this for Eccles is inconsistent with the conduct of reasoned argument.

Churchland's counter-argument to Eccles' PSRA consist.s in the claim that such a PSRA begs the question at issue. She states:

If determinism is correct, it does not in the least follow that we do not reason, that our behaviour is the outcome of compulsion rather than ratiocination. On the contrary, what rollows is that our reasoning and our reasoned behaviour is causally produced. So far from denying that humans are purposeful and reasonable, determinism is the thesis that there is a causal network which produces such behaviour.10

The anti-determinist on the other hand must "show that

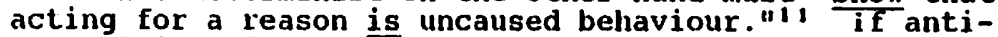
determinism is false, then human action must be then said, in Churchland's opinion, to be "contra-causally produced."

She compares the PSRA against determinism with a PSRA which could be made by the vitalist against the mechanist; and both she and Paul Churchland ${ }^{12}$ seem to consider the argument as being fairly decisive. The anti-vitalist's PSRA is this: if anti-vitalism was true, then there would be no vital spirit. But if there was no vital spirit a necessary condition for engaging in debate cannot be met, since the anti-vitalist would have to deny that $s / h e$ is alive, and this is a pragmatic contradiction. The argument is a non sequitur because there exists an alternative nonvitalist research programme, which challenges an undefended premise of the vitalists' argument; that 1 ife cannot be explained by any theory which does not incorporate vital spirit as its generative mechanism in the understanding of 1 ife processes.

Such argument shows that the PSRA has presupposed a false premise (or at least un undefended one) in the advancement of the argument. It does not show that the type of argument in question is invalid. There does in fact seen to be at least one position which can be clearly refuted: if a position was committed to affirming as true that nothing in the universe existed in any form of being at all, champions of such a position would be obviously defeated by a PSRA. It is difficult to imagine what could lead us to believe that this world was in actual fact the null-world. However the position does not seem to be capable of refutation by a SSRA, unless defenders of the ontological argument for the necessary existence of God are correct and that a 
null-world is not even rationally contemplatable. So what is at issue is the truth or falsity of the ASRC champions' argument. Churchland's vitalism/antivitalism analogy mere].y serves to draw to our attention the misconstruction made of the debate by the antivitalist.

Churchland's criticism of Eccles' PSRA must now be that in some way such an argument misconstructs the free will-determinism debate. I will argue that Eccles' PSRA does in fact do this. However, church] and has herself misconstructed the free wi]l-determinism debate. Consequently, both parties have clouded rather than cleared these issues.

Let us first outline what is incorrect in churchland's construction of the free will/determinism debate. The passages from her essay cited earlier indicate that she believes that determinists hold that our reasoning is "causally produced." Antideterminists must therefore hold that such acts. perhaps the paradigm exanple of free and purposive are "uncaused" and hence "contra-causally produced." Some anti-determinists may describe theinselves as "contracausalists," but if they are committed to claiming that human free action is a mysterious interference in nature their position will suffer great problems on many fronts. Would free human action for example be a miracle? If so, one nust now face all the traditional problems which this proposal involves. Perhaps these problems could be solved, but it is a price which the anti-determinist need not pay.

The anti-determinist need not claim that free action is uncaused and has no causal antecedents. Indeed one could as an anti-determinist grant that there is a set of causally antecedent conditions which are necessary for the performance of an allegedly free act F1. To be an anti-determinist one must deny that that $F 1$ is the result of a set of conditions $s$ which are causally sufficient for it. The universe for the determinist would appear to be one in which, given the state of the universe prior to my action F1, I "could not have done otherwise" than Fl. Explicating this phrase is a quite difficult and controversial matter, but I need not enter this debate lo make my point against Churchland. Determinists do in fact believe that human bchaviour is very strongly under the compulsive sway of natural law, so strongly that I could not do other than Fl given the prior state of the universe. However, they need not embrace the thesis of fatalism: that i will do Fl regardless of my beliefs, and whatever else I do. The Fatalist would claim that our lives in aIl respects resemble Oedipus' pitiful attempts to avoid his forecasted doon. But it was true before oedipus' birth, and for the vulgar fatalist impossible for him to avoid his fate by his own actions. The determinist need not view things so pessimistically: if Uedipus did avoid 
his fate, it does not follow that his evasive actions were done freely.

Determinism then might well be true even if falalism is false. 13 However, whatever answer is given to this question, it does seem that determinists wish to say much more than that human action is causally conditioned, and not all anti-determinists wish to say that free human action is "uncaused." To say what precisely these parties do wish to say and to find out whether their positions are in actual fact inconsistent (which compatiblilists deny) will require entering this debate further. But the point against Churchland has, however, been established: her statement of the freedom/determinism debate is incorrect.

This from a purely logical point of view invalidates Churchland's particular argument against Eccles. However, her point does in fact hold in my opinion against anti-determinists who advance such PSRA. It must be argued, for such an argument to be successful, that the relationship between the act of coming to know the truth of a proposition and causal factors which determine one's belief is "purely accidental." As Jordan puts it, if determinism is true
: . whether anyone believes jt, i.e., determin- ism, and what he considers trustworthy evidence and acceptable principles of inference are deter- mined altogether by conditions that have no as- sured congruence with the proposition's own merits or with criteria of sound argumentation whose validity consists of more than that we ac- cept them. 14

The argument here not only begs the question at issue but it misconstructs the determinist's position. The determinist would claim anything but that the act of coming to know the truth of a proposition and those causal factors which determine one's belief are merely "accidentally" or "randomly related," if this is meant to deny the very existence of the alleged causal connection. This is indeed self-contradictory. but is the fault of a mistaken argument of the auti-determinist, not of the determinist. The consistent determinist would not deny the brute facts that we do in fact reason philosophically. Rather our processes of reasoning are not free mental acts.

This clain might strike the anti-determinist as being question-begging in turn, and the debate at this point threatens to collapse. However, this is not so. The determinist will need to defend this position by an argument. It makes sense to criticize an argument on the grounds that it begs the question at issue, but not the mere formulation of a position. What needs to be shown here by the anti-determinist, by an independent argument, is that the process of reasoning precludes 
the acceptance of the thesis of determinism by any rational agent. Current PSRA are extrenely problematic: because they assume this from the onset. So while Churchland's argument itself fails, her criticism of Eccles is quite correct.

Before passing on to the second task of this paper some consideration to the PSRA of Boyle, Grisez and Tollefsen's should be given in the light of the following objection. They conceded that previous PSRA against determinism have failed insofar as they have begged the question against determinism. Determinism ("NfC") is self-refuting because rational affirmation of this position requires excluding freedom of will ("Sfc"), but the norms of rationality which we accept in our philosophical practices does not allow the exclusion of Sfc, so NfC cannot be rationally affirmed.16

Rationality norms include "paradignatic," "creative," "logical" and "technical" norms. paradigmatic norms provide standards for the evaluation of the normality of members of a class. Logical norns provide standards for the evaluation of discourse as consistent and coherence. Creative norms provide standards for the evaluation of the components of some work with respect to their unification in the total project. Finally, technical norms provide standards for the evaluation of action as it is a necessary condition for achieving one's ends. Both kinds of normality are asserted to be consistent with Nfc. ${ }^{17}$ Hence, neither of these kinds of normality entail sfc. However, Boyle, Grisez and Tollefsen argue at some length that neither of these kinds of nurmality can "exclude" Sfc. To take the logical norm, for example, sfc would only be excluded if it was self-contradictory and contingent upon a successful critigue of logical fatalism; $\mathrm{Sfc}$ does not appear to be excluded.

The premiss in this PSRA which is problematic in my opinion is this:

(P) If NEC is rationally affirmed, then the conditions obtain where sfic is rationally excluded.18

The defence of this premise is allegedly given in chapter Five, section $E$, of the book. We are told, then, that for a champion of Nfc to advarice Nfe, Nfc must be asserted as being true, or the tnost reasonable proposition to believe in a set of other propositions. In this sense it is quite correct to state that a chanpion of $\mathrm{Nfc}$ tusust: rationally exclude $\mathrm{SfC}$. If this was not done one would be committed to accepting two propositions which are mutually contradictory: both are such that they cannot simultaneously be true. However, what the Nfc is not committed to, is denying that $S f c$ must be excluded because it violates a rationality norm. The $\mathrm{Nfc}$ would accept that $\mathrm{Sfc}$ shonla not be rejected on such grounds and wolld welcome boyle, 
Grisez and Tollefsen's argument to this effect. However, $\mathrm{sfc}$ is rejected because the position is either false, or its arguments too weak to warrant rational assent, and the alleged PSRA collapses. The PSRA commits an equivocation between the grounds upon which a proposition may be rationally affirmed or excluded, and whether in fact a proposition violates paradigmatic, creative, logical or technical norms.

It is concluded that a sound PSRA against determinism has yet to be produced. It seems unlikely that any such PSRA could be constructed on presently envisageable grounds. Determinism is a coherent, substantial and challenging philosophical position. It could be met by anti-determinists by much ontological work, in charting out alternative and more plausible views of mind, causality and space and time than those accepted by present determinists. Whether determinism is in fact true, or even a reasonable position cannot be debated here.

\section{A critique of Everitt's Argument}

Nicholas Everitt has attempted to show by means of a PSRA that the doctrine of "straight-forward eliminative materialism" (SEM) can not be rationally assented to by any cognitive agent. SEM, a thesis most frequenty associated with Richard Rorty, 19 is the position that "there are no mental items, just as there are no unicorns." 20

The first problem which Everitt notes for the eliminative materialist is that he must, if this thesis is true, cease ascribing mental states, especially belief states, to himself. Yet to be an semist one must surely believe that one's thesis is true, and if so it is a necessary condition of an sEMist believing SEM that the thesis is in fact false.

In reply to this the SEMist might be led down the path of topic neutrality (TN), and to an easy slaughter. The TN thesis is the position that there is nothing about mental items in virtue of which they must be physical or non-physical. The SEMist I'N asserts that there are no M-beliefs (mentalistic-beliefs) and TN denies the truth of mentalism and TN believes that SEM is true. Everitt argues that if the SEMist accepts the $p$ thesis, that there is something about mental items in virtue of which they must be physical, the SEMist has no reason to be an SEMist rather than an identity theorist. Second, the TN thesis and mentalism were rival accounts of the referential nature of mental terms. The problem which Everitt believes to remain outstanding for the sEmist is to explain an initial acceptance of mentalism, while one reasons to the acceptance of SEM independent of whether the $p$ thesis is accepted once one has accepted SEM. 21 
Everitt's first reconstruction of the SEM argument takes the SEMist to be presenting a sound argument to this conclusion:

(Cl) SEM is true.

However, the SEMist must assent to this premise:

(1) The sEMist believes that mentalism is true.

The SEMist believes that mentalism is true because if (1) was false, then no SEMist has any more reason to accept SEM than a mind-body identity thesis. Everitt also argues in a far from clear and in a far from satisfactory manner that "if there is to be a reason (as distinct from his mistakenly thinking there is a reason) for denying the existence of the mental, (2) must be true as well,"22 i.e.,

(2) The mentalism thesis is true.

From (1) and (2) we deduce preinise (3):

(3) There is at least one non-physical mental item, this being the SEMist's belief that mentalism is true.

Premise (3) is inconsistent with (C1) since from (Cl) we can deduce a proposition $\left(\mathrm{Cl}^{*}\right)$ :

(C1*) There are no non-physical mental items

and (3) and ( $\mathrm{Cl}$ ) are inconsistent since by the conjunction rule we can deduce a proposition $\left(\mathrm{Cl}^{* *}\right)$ :

$\left(\mathrm{Cl}{ }^{* *}\right)$ There is at least one non-physical mental item and there are no non-pliysical ilems

which is an outright contradiction. It seems, then, that if Everitt's analysis is corlect, he has not shown that SEM is pragnatically self-refuting (PSRA), but has advanced a much stronger thesis, namely that: SEM is semantically self-refuting (SSRA). Let us call this argument, Argument $A$.

$A$ second argument, Argument B, involves epistemically weakening premise (2) C. Argument A:

(2a) The SEMist rationally helieves that the mentalism thesis is true.

This leaves open the possibility that mentalism is in fact false. The next prenise would also seem acceptable by a SEMist, Everitt alleges, who accepted (2a): 
(4) The Semist believes that he holds at least some beliefs.

From (2a) and (4) it is deduced that

(5) It is rational for the SEMist to believe that there are at least some non-physical mental items, these being at least his own beliefs.

From (2a), (4) and (5) it is deduced that

(6) It is not rational for a SEMist to believe SEM.

Argument $c$ is advanced to block a possible rejoinder which could be made to a conception of rational belief presupposed by Argument B: if it is rational for someone $S$ to believe that $p$, and $p$ is inconsistent with $q$, it is not rational for $s$ to believe that $q$ : $s$ must reasonably believe that $p$ and $q$ are inconsistent. The SEMist enlightened by Argument $B$ is faced by this argument:

(C) . . . if the SEMist gives up his belief in SEM, then of course he is no longer an sEMist; if he gives up his belief that there are non-physical mental items, then he must also give up either the mentalism thesis or liis belief that the holds some beliefs. If we assume that the latter is contingently very improbable, all that is left is for him to abandon the mentalism thesis. But if he abandons the mentalism thesis, there is no reason for his materialism to be eliminative. ${ }^{23}$

Argument $c$ can be stated more explicitly as follows:

(2) The mentalism thesis is true.

(7) I have some beliefs.

'lierefore,

(8) There are some non-physical mental items ((2), (7)).

(9) (8) is inconsistent with SEM, by definition of "SEM".

(10) If (8) is false, then either (2), (7) or both (2)) and (7) are false (as (2) and (7) entail (8)).

(11) (7) is true.

Therefore,

(12) If (8) is false, then (2) is false $(10),(11))$. 
(13) If (2) is false, then SEM has no adeguat.e rationale.

Therefore,

(14) If (8) is false, then SEM has no adequate rationale.

(15) If (B) is true, then SEM is false (9).

Therefore.

(16) Either SEM is false or SEM has no adequate rationale ((14), (15)).

This trio of arguments presents a prima facie strong challenge to SEM, but it is a challenge which the sEMist can meet. My criticism here will centre upon premises (2) and (2a), and contrary to Everitt, the SEMist need not accept these premises precisely as he has stated them. Consequently all three arguments are unsound.

First let us be clear about what mentalism in fact is. Mentalism is the thesis, according to Everitt, which asserts this:

(M1) The mental, if it exists, is non-physical. ${ }^{24}$

The assertion (M1) can be restated, without changing either its sense or truth value, as (M2):

(M2) If the mental exists then the mental is nonphysical.

Is it in fact the case that the sEMjst accepts (M2)? Yes, indeed it does seem to be so. So let us next review what the sEM thesis is. SEM is the following claim:

(SEM*) If SEM is true, then there are no mental items (just as there are no unj.corns).

It seems though that even the mentalist would accept (SEM*). (SEM*) is in fact a necessary truth, the source of its necessity deriving from the definition of the SEMist position itself. However the mentalist would argue that there are in fact mental items, while the eliminative materialist would deny this. The SEMist can accept both propositions (M2) and (SEM*) because they are in fact necessary truths. But this is consistent with the assertion that "mentalism" is false insofar as the mental does not exist. Hence the mentalist position must encompass not only an acceptance of (M2) but also this claim: 
Everitt's challenge to sEMists is to explain how in fact one can initially accept "mentalism", yet argue for SEM. I have pointed out that the sEMist does not in fact accept mentalism insofar as mentalism is the claim (M2) and (M3). What I must now do is to outline how in fact a philosopher might come to believe a thesis which is so challenging to our common sense view of the world as SEM.

The reasoning here is quite simple. The sEMist does in fact believe that the common sense view of the world is very seriously flawed. The SEM would argue that such a world view does not consitute a pretheoretical given, because common sense positions contain metaphysical assumptions. Yet philosophy. while it cannot help but begin with common sense positions (since the philosopher must grow up in a human society), has never been content with accepting traditional cultural wisdom. Philosophers have and should challenge the wisdom of the status quo. And this is precisely what has occurred in the history of philosophy. Zeno attacked such a well entrenched view that things in fact undergo change in the world, and that there is plurality at all. Sceptics have denied that we know anything at all, and eliminative materialists have denied both that the mental entities of ordinary language exist, as well as the material objects of ordinary language. 25

The SEMist claims that future neurophysiological research may well lead us to conclude that the mentalist's mental entities are in fact brain processes. The relationship of these mental entity terms to the theoretical entity terms of a future neuropliysiology would be the same as that which holds between a theoretically eliminated term such as "quantity of caloric fluid" and an at present accepted term such as "the mean kinetic energy of molecules." From the perspective of contemporary thermodynamics the referent of the former term does not exist, and the observational and explanatory role once played by such a term is taken over by thermodynamics. l,ikewise, a Iinguistic reform may in fact occur whereby the observational and explanatory role played by mentalistic terms may be taken over by the sEMist's neuropliysiological language. $n t$ this point, it justifiably could be said by the semist that mental items do not exist, just as it is said that caloric fluid and vital spirits do not exist.

The SEMist is proposing a quite radical modification of our present view of the world. Paul churclsland"26 imagines a new form of "language" which "could be learned and used by our innale systems.. . since it would reflect the underlying structure of our: cognitive activities in greater: detail than does nat- 
ural language".27 Compound "strings" of this new mode of communication (uebersaetzen) are not evaluated as true or false, and what we at present take as relations of entailment will no longer hold between uebersaetzen components. Flilosophical argument itse It wiIl have then become a thing of the past. Richard Rorty, in fact believes that the received view of philosophy is already not only a degenerating research programme, but one already decayed.28 he himself suggests the replacement of philosophy by hermeneutics; The radical SEMist would no doubt construct some uebersaetzen activity to busy any of today's philosophers whose working 1 fe extends into this social order.

If this sketch of the SEMist programme is accurate, then Everitt's argument does in fact beg the question against the SEMist. The SEMist is proposing not only a conceptual-technological revolution, but a socioinstitutional revolution more radical than that ever conceived by social theorists. The Anti-sEMist stands in the same position as for example a liberal theorist defending the inevitability of capitalisl against a Marxist, on the grounds that the acquisition and possession of private property by individuals is a necessary condition for a flourishing life of the individuals as well as for social harmony. The argument in the latter case presupposes the inevitability of those very social institutions, and a view of human nature which the Marxist explicitly rejects. In the former case, the question is also begged, since a common sense world view is assumed, and it is the inevitability of this position which the radical SEH questions.

Perhaps SEM would be incoherent if there was in fact a transcendental argument demonstrating the absolute necessity of commonsense concepts. But such a strategy faces two problems. First, the question of the justification of transcendenta] modes of argumentation is an outstanding philosophical controversy. Second, it must fail against Paul Churchland's scenario of the abandonment of natural language and it.s replacement by uebersaetzen, since it seems questions of truth and falsity and validity will no longer arise, and questions of argumentation are then uecessarily out of the question. conseguently such a radical SEM programme could only be implemented or not implemented; it could not be argued for. Its acceptance or rejection is then a political question.

Self-referential arguments are a powerful philosophical weapon of critique. However, there are ways of escaping such arguments. This is not to say that determinism and SEM are true or even reasonable. Both positions can be criticized, but most plausibly from the perspective of an alternative comprehensive metaplysical system which would allow a transcendence of both philosophical problems. l.et us audition for such 
reconstructions, but not on the basis of selfreferential arguments.

\section{FOOTNOTES}

'P. Smith Churchland, "Is Determinism Self-refuting?", Mind $40(1981)$, pp. 99-101.

${ }^{2}$ N. Everitt, "A Problem for the Eliminative Materialist," Mind 40 (1981), pp. 428-434.

${ }^{3}$ For a more detailed discussion of ASRC see 3 . M. Boyle, "Self-Referential Inconsistency, Inevitable Falsity and Metaphysical Argumentation" Metaphilosophy 3. (1972), pp. 25-42; J. M. Boyle, G. Grisez and 0 . Tollefsen, Free Choice: A Self-Referential Argument (Notre Dame: University of Notre Dame Press, 1976).

${ }^{1} \mathrm{Cf}$. R. Carnap, Introduction to Semantics (Cambridge, MA: llarvard University Press, 1942), pp. 8-9.

"E.g., P. Unger, Ignorance (Oxford: Oxford University Press, 1975).

${ }^{6}$ An excellent discussion of this issue is given by c. S. Chihara, ontology and the vicious-circle Principle (1 thaca and London: Cornell University Press, 1973).

${ }^{7}$ Cf. T. Drange, "The Paradox of the Non-Communicator," Philosophical studies 15 (1964), pp. 92-96.

${ }^{8}$ Russell's claim that all self-referential statements are meaningless, is false. As we have seen here ASRC follows closely the liar antinomy argument, but shows that some positions are necessarily false, not true if and only if they are false.

9 J. C. Eccles, "Brain and Free Will," in G. Globus, G. Maxwell and I. Savodnik (eds.), Consciousness and the Brain: A Scientific and Philosophical Inquiry (New York: Pleñum Press, 1976), pp. 101-121. Citation p. 101.

10 Churchland, "Is Determinism Self-Refuting," op. cít., Note 1 , p. 99 .

11 Ibjd. , p. 100 . 
${ }^{12} \mathrm{P}$. M. Churchland, "Eliminatjve Materialism and the Propositional Attitudes," Journal of Philosoply 78 (1981), pp. 67-90. Citation, pp. 89-90.

${ }^{13}$ For arguments that it is, see $S$. Haack, Deviant Logic (Cambrjdge: Canbriage Unjuersity Press, 1974) Chp. 4 and R. Routley, Exploring Meinong's Jungle (ANU Monograph No. 3, Canberra, 1980), pp. 405-409.

$14 \mathrm{~J}$. N. Jordan, "Determinism's Dilemma," Review of Metaphysics 23 (1969), pp. 48-66. Citation, p. 54.

${ }^{15}$ Boyle, Grisez and Tollefsen, Free choice, op. cit., note 3 .

16 Ibid. . pp. 154-155.

17 Ibid. , p. 158 .

${ }^{18}$ Ibid. , p. 163.

${ }^{19} \mathrm{Cf}$. R. Rorty, "Mind-body, Identity, privacy and Categories," Review of Metaphysjes 19 (1965), pp. 2454; "In Defeñse of EIiminative Materialism," Review of Metaphysics 24 (1970), pp. 112-121.

${ }^{20}$ Everitt, "A Problem for the Eliminative Materialist," op. cit., note 2 , p. 428 .

21 Ibid. . p. 432.

22 Ibid. . p. 432 .

23 Ibid. . p. 434 .

24 Ibid.. p. 428 .

2 scf. T. Guleserian, "On Two Aspects of Eliminative Materialism," Philosophy of Science 38 (1971), pp. 282289.

26. Churchland, "Eliminative Mateiralism and the Propositional Attitudes," op. cit.. note 12 , pp. 86-88.

27 Ibid.., p. 86.

${ }^{28} \mathrm{Cf}$. R. Rorty, Philosophy and the Mirror of Nature (Princetull: Frinceton University press, 1979). 